This item was submitted to Loughborough's Research Repository by the author.

Items in Figshare are protected by copyright, with all rights reserved, unless otherwise indicated.

\title{
Probing the interplay between factors determining reaction rates on silica gel using termolecular systems
}

PLEASE CITE THE PUBLISHED VERSION

http://dx.doi.org/10.1039/c2pp25171j

\section{PUBLISHER}

(c) Royal Society of Chemistry and Owner Societies

\section{VERSION}

AM (Accepted Manuscript)

\section{PUBLISHER STATEMENT}

This work is made available according to the conditions of the Creative Commons Attribution-NonCommercialNoDerivatives 4.0 International (CC BY-NC-ND 4.0) licence. Full details of this licence are available at: https://creativecommons.org/licenses/by-nc-nd/4.0/

\section{LICENCE}

CC BY-NC-ND 4.0

\section{REPOSITORY RECORD}

Kirkpatrick, lain, David R. Worrall, Sian L. Williams, Craig J.T. Buck, and Rafael G. Meseguer. 2019. "Probing the Interplay Between Factors Determining Reaction Rates on Silica Gel Using Termolecular Systems". figshare. https://hdl.handle.net/2134/16135. 


\title{
Probing the interplay between factors determining reaction rates on silica gel using termolecular systems
}

\author{
Iain Kirkpatrick, David R. Worrall,* Siân L. Williams, Craig J. T. Buck and Rafael G. Meseguer \\ Received (in $X X X, X X X) X$ th $X X X X X X X X X 20 X X$, Accepted $X$ th $X X X X X X X X X 20 X X$ \\ ${ }_{5}$ DOI: $10.1039 / b 000000 x$
}

In this study we have compared energy and electron transfer reactions in termolecular systems using a nanosecond diffuse reflectance laser flash photolysis technique. We have previously investigated these processes on silica gel surfaces for bimolecular systems $s^{1,2}$ and electron transfer in termolecular systems ${ }^{3,4}$. The latter systems involved electron transfer between three arene molecules with azulene acting as a

10 molecular shuttle. In this study we present an alternative electron transfer system using trans $\beta$-carotene as an electron donor in order to effectively immobilise all species except the shuttle, providing the first unambiguous evidence for radical ion mobility. In the energy transfer system we use naphthalene, a structural isomer of azulene, as the shuttle, facilitating energy transfer from a selectively excited benzophenone sensitiser to 9-cyanoanthracene. Bimolecular rate constants for all of these processes have 15 been measured and new insights into the factors determining the rates of these reactions on silica gel have been obtained.

\section{Introduction}

The photochemistry and photophysics of molecules adsorbed on metal oxide ${ }^{1-30}$ and other surfaces ${ }^{31-45}$ have been the subject of 20 extensive studies. Silica gel is widely used in industry and a greater understanding of reaction kinetics on this and similar materials would be invaluable, allowing for enhancement of these processes.

The excitation and multi-photon ionisation of arenes and their 25 subsequent energy and electron transfer reactions on silica gel have been previously reported ${ }^{1-4,7,8,12-15}$. The decay of excited state and radical ion species on silica gel is complicated due to the heterogeneity of the surface and rates rarely conform to simple exponential kinetics. The model described by Albery et $30 \mathrm{al}^{46}$ has been used to characterise the data sets, ensuring a comprehensive exploration of the parameter space in order to obtain a global optimum value for the rate parameters as described in reference 1.

In previous studies we have shown evidence for energy and 35 electron transfer reactions in these systems as being largely dependent upon the rates of diffusion ${ }^{1-4}$, and in the case of anthracene / azulene systems, rates of reaction are governed by the rate of diffusion of azulene which is more mobile than the anthracene moeities. There, energetics were demonstrated to have 40 a significant role in determining electron transfer rates ${ }^{1,7,15}$, and we have shown a Marcus-type dependence of rate on the free energy for electron transfer ${ }^{1,7,15}$. In that study we also found evidence for an additional influence from steric factors ${ }^{1}$ when going from mono to di-substituted naphthalene derivatives. We ${ }_{45}$ have also previously studied electron transfer ${ }^{4}$ and energetics ${ }^{3}$ in a ter-molecular system with anthracene (or anthracene-9carboxylic acid), azulene and perylene.
Here we present a study of electron transfer in an anthracene9-carboxylic acid / azulene / $\beta$-carotene system. In this case we 50 expect that azulene will be the only mobile species on the silica gel surface, and in electron transfer from such a large molecule as $\beta$-carotene one might expect that any steric influence to be considerably greater than that observed in the systems referred to above. It should be noted that whilst the $\beta$-carotene is relatively ${ }_{55}$ large, its size (estimated at 2.8nm using HyperChem) does not preclude access to the porous structure of the silica gel. Adsorption to the surface is via London (dispersive) forces or, in the case of for example anthracene-9-carboxylic acid, the considerably stronger hydrogen bonding interactions.

60 One of our goals has been to expand these studies to include energy transfer in a termolecular system and we report upon such a system, using benzophenone as the primary absorber and energy donor, with naphthalene and 9-cyanoanthracene as energy acceptor/donor and acceptor, respectively.

\section{${ }_{65}$ Experimental}

Samples were prepared as follows: Silica gel (Davisil grade 635, 60-100 mesh, $6 \mathrm{~nm}$ pore size, surface area $480 \mathrm{~m}^{2} \mathrm{~g}^{-1}$; Aldrich Chemical Co.) was dried at a temperature of $125{ }^{\circ} \mathrm{C}$ under a vacuum of $5 \times 10^{-5}$ mbar for 8 hours, and the vessel re70 pressurised with dry nitrogen. Anthracene-9-carboxylic acid (minimum 99\%, Aldrich Chemical Co.), azulene (99\%, Aldrich Chemical Co.), trans $\beta$-carotene (Aldrich Chemical Co.), benzophenone (99\%, Aldrich Chemical Co.), naphthalene (99\%, scintillation grade, Aldrich Chemical Co.), and 975 cyanoanthracene (99\%, Aldrich Chemical Co.) were dissolved in acetonitrile (spectrophotometric grade, Aldrich Chemical Co.) or chloroform (spectrophotometric grade, Aldrich Chemical Co.) 
and a known weight of the resulting solution added to the dried silica gel. The mixture was allowed to equilibrate for a period of one hour, with periodic agitation. The solvent was then removed under vacuum to a pressure of $5 \times 10^{-5}$ mbar. The resulting 5 sample was then sealed under vacuum into a cylindrical glass cuvette (22 mm diameter $\times 10 \mathrm{~mm}$ path length). Sample loadings were determined from the mass of solution added to the silica gel

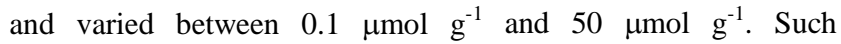
concentrations correspond to a low surface coverage, with the 10 highest being less than $0.1 \%$ of a homogeneous 2D surface monolayer.

Ground state diffuse reflectance spectra were recorded using a Perkin-Elmer Lambda Bio 40 spectrophotometer equipped with a Spectralon integrating sphere. A highly packed barium sulfate 15 sample was employed as a reference.

The nanosecond diffuse reflectance laser flash photolysis apparatus has been described previously in references 24 and 47. In the flash photolysis experiments, excitation of the samples was carried out using the third harmonic (355 nm, $5 \mathrm{~ns}$ fwhm, $110 \mathrm{~mJ}$ 20 pulse $^{-1}$ ) of a Surelite I Nd:YAG laser (Continuum). The pulse energy was attenuated by varying the active Q-switch delay to ensure that transient reflectance changes were kept below $10 \%$, where the change in reflectance is directly proportional to the concentration of transient species. Diffusely reflected analysing 25 light from a $300 \mathrm{~W}$ xenon arc lamp (Oriel) was collected and focussed onto the entrance slit of an $f / 3.4$ grating monochromator (Applied Photophysics) and detected with a side-on photomultiplier tube (Hamamatsu R928). The resulting signals were captured in real-time by a LeCroy LT364 Waverunner 30 digitising oscilloscope at $1 \mathrm{GS} / \mathrm{s}$.

Transient decay data has been analysed using the model of Albery et $a .^{46}$ which treats kinetic decays as a log Gaussian distribution of rate constants, according to eqn. 1

35

$$
\frac{\mathrm{C}}{\mathrm{C}_{0}}=\frac{\int_{-\infty}^{\infty} \exp \left(-\mathrm{t}^{2}\right) \exp [-\bar{k} \mathrm{t} \exp (\lambda)] d t}{\int_{-\infty}^{\infty} \exp \left(-\mathrm{t}^{2}\right) d t}
$$

which was transformed to have finite integrals as described in the appendix of reference 46 . Here $\mathrm{C}$ and $\mathrm{C}_{0}$ are transient concentrations at times $t=t$ and $t=0$ after the laser pulse, $\gamma$ is the 40 width of the distribution and $\bar{k}$ is the mean rate constant. At low sample loadings and small reflectance changes (less than 10\%), C and $\mathrm{C}_{0}$ can be replaced by $\Delta \mathrm{R}$ and $\Delta \mathrm{R}_{0}$, the reflectance changes at times $t=t$ and $t=0$ respectively. This model is applicable in systems such as these where transient species are either spectrally 45 seperated from one another, decay on very different timescales, or where the quantum yields of potentially interfering species are negligible (vide infra). We have also established that the fitting parameters are not dependent on the analysing wavelength over the absorption band of the species of interest in these systems. 50 Additionally, we have successfully applied this model in the analysis of data in other termolecular systems ${ }^{3,4}$, and hence the data presented here can be directly compared with our previously published work.

\section{Results and discussion}

${ }_{55}$ Using a nanosecond laser flash photolysis technique, we have measured transient absorption spectra and bimolecular rate constants for termolecular systems on silica gel surfaces; electron transfer with anthracene-9-carboxylic acid / azulene / trans $\beta$ carotene and triplet-triplet energy transfer within the 60 benzophenone / naphthalene / 9-cyanoanthracene system.

\section{Electron transfer}

Previously we have chosen anthracene, azulene and perylene to investigate electron transfer in a ter-molecular system ${ }^{3,4}$. In that 65 study, evidence for the mobility of the azulene radical cation was found based upon the relative rates of the rise of the perylene radical cation absorption in the presence and absence of azulene. For this work $\beta$-carotene was selected as a suitable electron donor since, due to its large size, it would be expected to be immobile 70 on the silica gel surface (at least on the timescale of the experiments conducted here). In addition it has an appropriate oxidation potential for the electron transfer to take place, being lower than azulene, which we have measured by cyclic voltammetry and found to be $0.59 \mathrm{~V}$ ( $\beta$-carotene) and $1.01 \mathrm{~V}$ 75 (azulene) vs. Ag / $\mathrm{AgCl}$ (c.f. $1.04 \mathrm{~V}$ previously ${ }^{1}$ ). This value is in close agreement to that found for $\beta$-carotene by Rusling et al. ${ }^{48}$ of $0.57 \mathrm{~V}$ vs. SCE (+ $45 \mathrm{mV}$ vs $\mathrm{Ag} / \mathrm{AgCl}$ ). In the present study, the lack of mobility of the $\beta$-carotene on the silica gel surface was confirmed experimentally in the anthracene-9-carboxylic acid / $\beta$ 80 carotene system where no electron transfer occurred following laser excitation. This is in contrast to previous studies of the anthracene-9-carboxylic acid / perylene system ${ }^{3}$ where a relatively slow (compared with values for electron donors azulene and naphthalene in bimolecular systems ${ }^{1,2}$ ) electron transfer was 85 clearly observed.

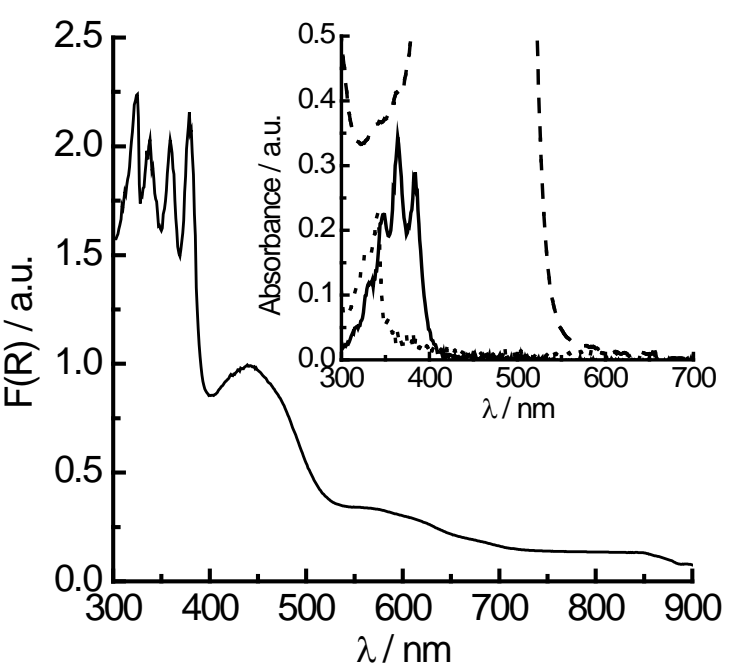

Fig. 1 Ground state diffuse reflectance spectrum of anthracene-9carboxylic acid with azulene and $\beta$-carotene on silica gel. Sample loadings are are all $1.0 \mu \mathrm{mol} \mathrm{g}^{-1}$. Inset shows absorption spectra of 90 anthracene-9-carboxylic acid (solid line), azulene (dotted line) and $\beta$ carotene (dashed line) in chloroform. Sample concentrations were all $4 \times$ $10^{-5} \mathrm{~mol} \mathrm{dm}^{-3}$. 
Figure 1 shows the ground state diffuse reflectance and individual solution spectra of the termolecular system. At the loadings studied an appreciable proportion of the excitation 5 radiation is absorbed by the anthracene-9-carboxylic acid. Although there is absorption by both azulene and $\beta$-carotene, neither of these gives rise to interfering transient species. If azulene is co-adsorbed to form the termolecular system, then electron transfer can be observed from azulene to the anthracene 10 radical cation, followed by electron transfer from the $\beta$-carotene to the azulene radical cation. This demonstrates unambiguously that the azulene radical cation is mobile on the surface. Furthermore, in this particular system, azulene and its radical cation are the only mobile species on these time scales. Fig. 2 15 shows the transient spectrum that was obtained following $355 \mathrm{~nm}$ pulsed laser excitation of the anthracene-9-carboxylic acid / azulene / $\beta$-carotene system.

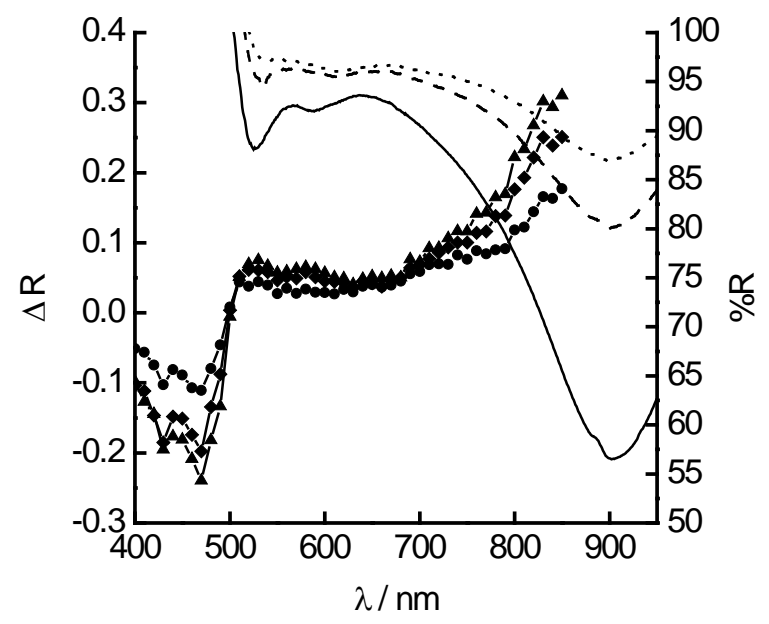

Fig. 2 Transient absorption spectrum ( $\Delta \mathrm{R}$ versus $\lambda$ ) of anthracene-920 carboxylic acid / azulene / $\beta$-carotene following $355 \mathrm{~nm}$ pulsed laser excitation. Sample loadings are 5, 2 and $1 \mu \mathrm{mol} \mathrm{g}^{-1}$ respectively. Spectra were measured at $5 \mathrm{~ms}(\bullet), 50 \mathrm{~ms}(\diamond)$ and $200 \mathrm{~ms}(\boldsymbol{\Delta})$ after the laser pulse.

Reflectance spectrum (\%R versus $\lambda$ ) of anthracene-9-carboxylic acid / 25 azulene / $\beta$-carotene following $355 \mathrm{~nm}$ pulsed laser excitation. Sample loadings are 5, 2 and $1 \mu \mathrm{mol} \mathrm{g}{ }^{-1}$ respectively. Spectra were recorded at 1 min (solid line), 5 min (dashed line) and $10 \mathrm{~min}$ (dotted line) after the laser pulse.

30 Several bands can be seen following excitation and subsequent electron transfer, which are not present in the absence of azulene. Given the short lifetime of the $\beta$-carotene excited triplet state we attribute these bands to the $\beta$-carotene radical cation ${ }^{49-51}$. A depletion of the ground state at $470 \mathrm{~nm}$ is observed with kinetics 35 similar to the formation of the band above $800 \mathrm{~nm}$. The radical cation species is persistent enough to be seen over longer time scales (minutes) using a steady-state reflectance spectrophotometer. The instrument was blanked using the sample itself prior to irradiation, which was then subjected to two shots 40 of $355 \mathrm{~nm}$ laser radiation at maximum output (measured as approx. $80 \mathrm{~mJ}$ ). The reflectance spectrum was measured on the time scale of minutes after laser excitation (note that this spectrum is uncorrected for emission in the 400-500nm region; in the transient absorption data, from which the kinetic parameters 45 are extracted, emission is corrected for). In this case, only extremely long lived species remained measurable. By contrast, metastable species such as excited triplet states decayed within seconds (or even milliseconds) after irradiation. The spectra are shown in Fig. 2.

50 At longer times after the laser pulse, the reflectance spectrum was found to be very similar to the transient absorption spectrum. We chose to measure the kinetics of formation of this species at $515 \mathrm{~nm}$. There is significantly more reflectance change at longer wavelengths, but the signal to noise ratio in the transient decays 55 was found to be worse in this region.

The kinetics of the formation of the $\beta$-carotene radical were measured as a function of azulene loading. In all cases, the loadings of anthracene-9-carboxylic acid and $\beta$-carotene were kept constant at 1.0 and $0.25 \mu \mathrm{mol} \mathrm{g}{ }^{-1}$ respectively. Fig. 3 shows $60 \mathrm{a}$ plot of mean rate constant for formation of the $\beta$-carotene radical at $515 \mathrm{~nm}$ versus azulene loading which was analysed according to eqn. 2 .

$$
\bar{k}=\bar{k}_{0}+k_{q}^{\prime} \text { [quencher] }
$$

${ }_{65}$ Here $\bar{k}_{0}$ is the mean rate constant in the absence of a quencher (electron donor) and should be zero in the case of electron transfer. The gradient of a plot of observed mean rate constant, $\bar{k}$ versus quencher concentration then gives the bimolecular rate constant, $k_{q}^{\prime}$, or in this case $k_{\mathrm{et}}$, for electron transfer.

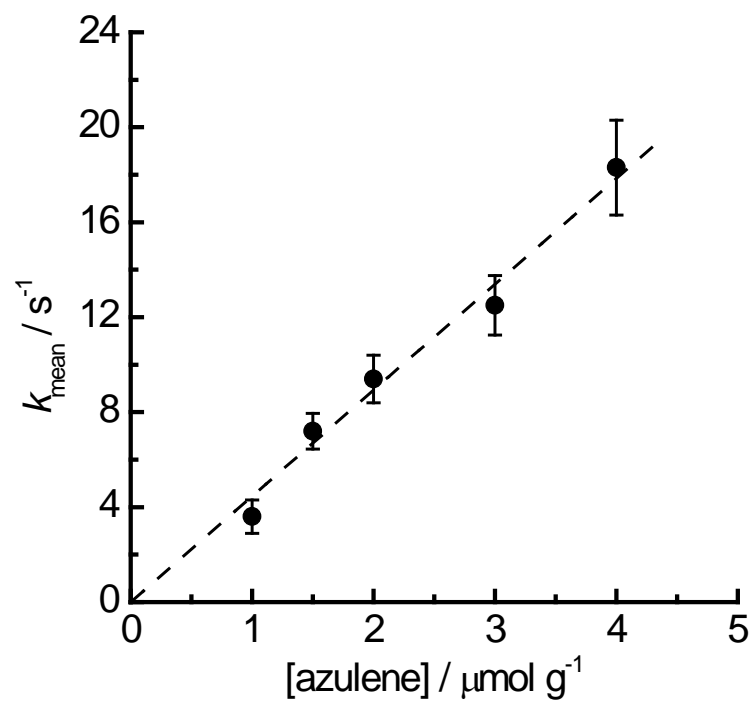

70

Fig. 3 Plot of mean rate constant versus azulene loading for anthracene9-carboxylic acid / azulene / $\beta$-carotene $\left(1.0, \mathrm{x}, 0.25 \mu \mathrm{mol} \mathrm{g}^{-1}\right)$ following $355 \mathrm{~nm}$ laser excitation. Formation of the $\beta$-carotene radical cation was monitored at $515 \mathrm{~nm}$.

75

We have measured the bimolecular rate constant for electron transfer between $\beta$-carotene and azulene to be $4.5 \pm 0.2 \times 10^{6} \mathrm{~g}$ $\mathrm{mol}^{-1} \mathrm{~s}^{-1}$. This can be compared with our previously reported values of $1.1 \times 10^{10} \mathrm{~g} \mathrm{~mol}^{-1} \mathrm{~s}^{-1}$ and $9.5 \times 10^{9} \mathrm{~g} \mathrm{~mol}^{-1} \mathrm{~s}^{-1}$ for the 80 anthracene-9-carboxylic acid / azulene / perylene ${ }^{4}$ and anthracene 
/ azulene ${ }^{2}$ systems respectively. This significantly lower rate can be attributed to steric (entropic) factors involved in the electron transfer process, a phenomenon invoked previously by us to explain significantly reduced electron transfer rates in 5 bimolecular systems involving sterically hindered electron donors ${ }^{1}$. It is therefore expected that the marked reduction in the rate of electron transfer observed when employing a molecule as large as $\beta$-carotene is the result of the efficiency being dependent upon the approach between donor and acceptor. Thus, the rate of 10 electron transfer between $\beta$-carotene and azulene lies well outside of the Marcus-type domain reported by ourselves in reference 1. This is illustrated in Fig 4.

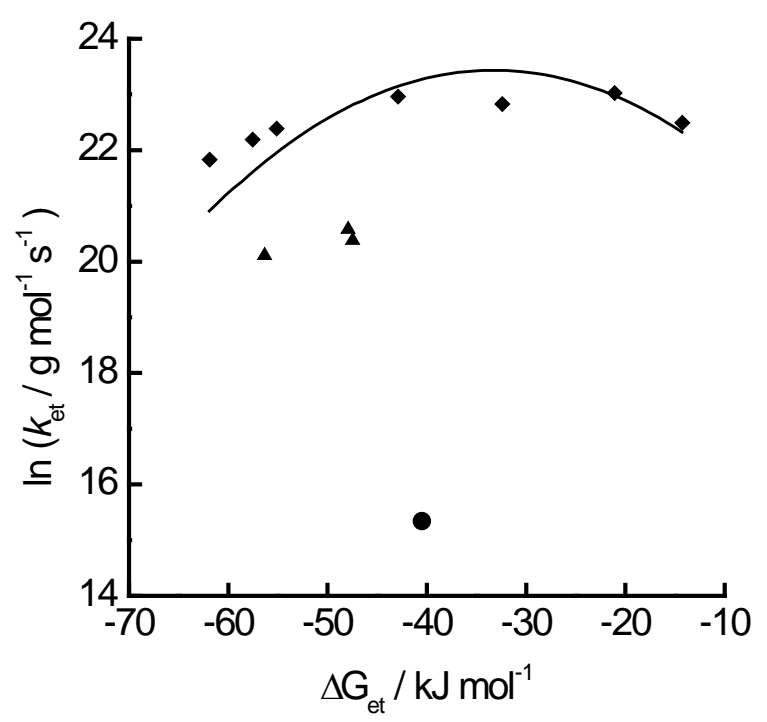

15 Fig. 4 Plot of $\ln k_{\text {et }}$ versus $\Delta \mathrm{G}_{\mathrm{et}}$ for a series of arene electron donors and their mono-substituted derivatives $(\diamond)$, dimethyl / isopropyl naphthalene derivatives $(\boldsymbol{\Delta})$ and updated with $\beta$-carotene $(\bullet)$ included for comparison. Solid line shows fit according to the Marcus equation. Previously published with full details in reference 1 .

\section{Energy transfer}

For the first time we have investigated triplet-triplet energy transfer in a termolecular system. In this system benzophenone is the primary absorber, with the first excited triplet state being 25 formed following $355 \mathrm{~nm}$ laser excitation. Naphthalene does not absorb in this region and hence its triplet state can only be formed via energy transfer from benzophenone. This is an exothermic process since naphthalene has a lower triplet state energy than benzophenone $e^{52,53}$. Thomas et al. ${ }^{5}$ have previously suggested that 30 benzophenone is immobile on silica gel surfaces and hence dynamic quenching is dependent on the motion of the naphthalene. The final energy sink is 9-cyanoanthracene, chosen for its lower triplet state energy than naphthalene, and its triplet quantum yield close to zero ${ }^{54}$. Hence, even though this species 35 absorbs at the laser wavelength, population of the triplet state occurs only via energy transfer.

The transient spectrum for the benzophenone / naphthalene system is shown in Fig. 5.

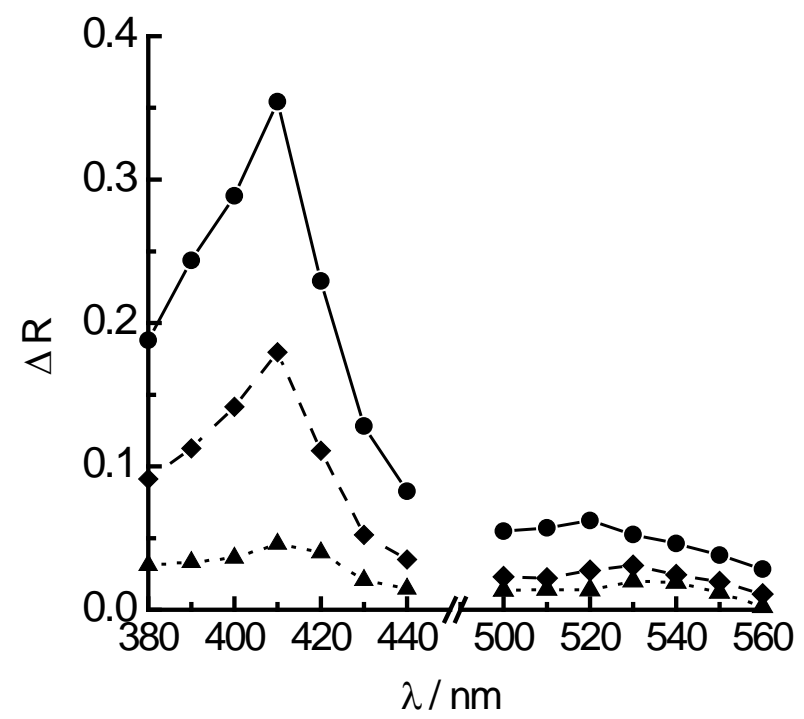

40 Fig. 5 Transient absorption spectra of benzophenone / naphthalene on silica gel following $355 \mathrm{~nm}$ pulsed laser excitation. Sample loadings are 50 and $1.0 \mu \mathrm{mol} \mathrm{g}^{-1}$ respectively. Spectra were measured at $20 \mu \mathrm{s}(\bullet), 50$ $\mu \mathrm{s}(\boldsymbol{\vee})$ and $100 \mu \mathrm{s}(\boldsymbol{\Delta})$ after the laser pulse.

45 The bands present at 520 and $410 \mathrm{~nm}$ are consistent with excited triplet states of benzophenone $e^{40,52,53}$ and naphthalene adsorbed on silica ge ${ }^{52,53}$. This experiment was repeated using a tenfold increase in naphthalene loading. A 50\% decrease in the initial reflectance change of the benzophenone triplet state was 50 seen, consistent with efficient triplet state quenching by naphthalene. The naphthalene triplet state is produced efficiently even at the lower loading with a $\Delta \mathrm{R}_{0}$ of 0.41 versus 0.33 for high and low loadings respectively. In the presence of 9cyanoanthracene, the transient spectrum (Fig. 6) shows an

55 additional broad absorption from the excited triplet state of this species, with absorption bands at 430 and $460 \mathrm{~nm}^{51}$, indicating energy transfer has occurred from benzophenone to naphthalene to the lower lying 9-cyanoanthracene triplet state. Direct production of the latter species is negligible ${ }^{54}$.

60

Kinetic analysis of the decay and formation of these excited triplet states has allowed us to measure bimolecular rate constants for the two energy transfer processes in this termolecular system. However, it should be noted that the initial energy transfer from 65 benzophenone to naphthalene was examined in the absence of 9cyanoanthracene in order to avoid complications from spectral overlap between the naphthalene and 9-cyanoanthracene. A typical transient kinetic decay with residuals is shown in Fig. 7 for the naphthalene triplet state. 


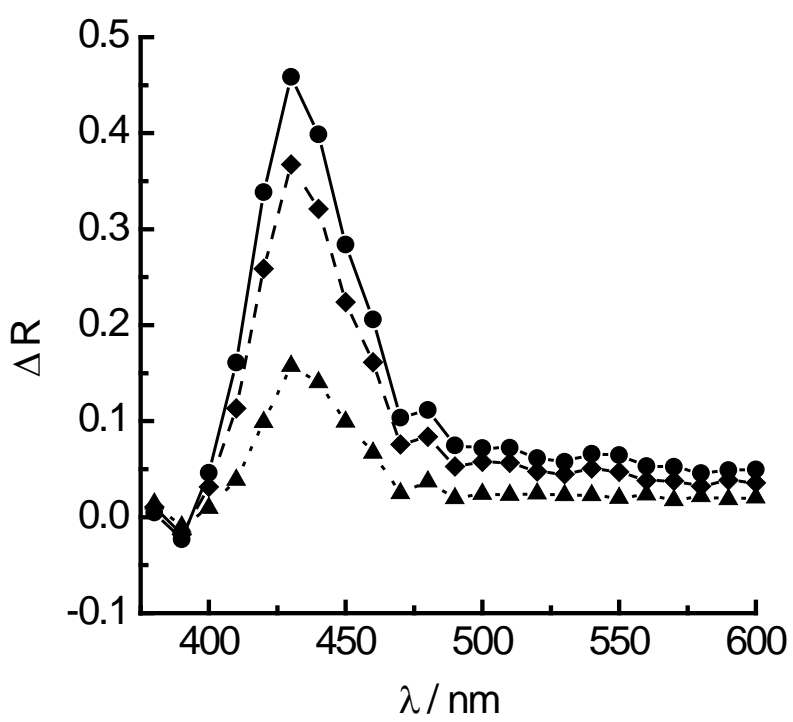

Fig. 6 Transient absorption spectrum of benzophenone / naphthalene / 9cyanoanthracene on silica gel following $355 \mathrm{~nm}$ pulsed laser excitation. Sample loadings are 50, 10 and $0.5 \mu \mathrm{mol} \mathrm{g}^{-1}$. Spectra were measured at $5100 \mu \mathrm{s}(\bullet), 5 \mathrm{~ms}(\bullet)$ and $20 \mathrm{~ms}(\boldsymbol{\Delta})$ after the laser pulse.

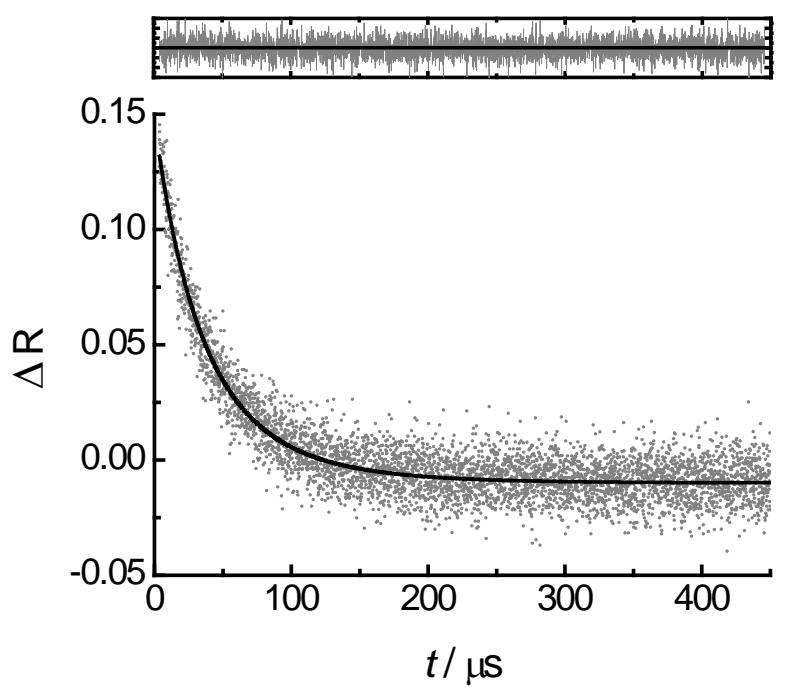

Fig. 7 Transient decay and residuals (inset top) for benzophenone 10 sensitised naphthalene excited triplet state on silica gel, monitored at 410 $\mathrm{nm}$. Sample loadings are 50 and $1.0 \mu \mathrm{mol} \mathrm{g}{ }^{-1}$ respectively. Fitting by the Albery dispersive kinetic model yields $\bar{k}=2.55 \times 10^{4} \mathrm{~s}^{-1}$ and $\gamma=0.6$ corresponding to a global minimum in reduced $\chi^{2}$.

15 The decay was monitored using both the transient absorption decay at 530nm and phosphorescence decay at 430nm. The latter significantly improves the signal to noise ratio at higher naphthalene loadings and rate constants were found to be the same within experimental error, irrespective of monitoring 20 technique. Energy transfer from the naphthalene shuttle to 9- cyanoanthracene was examined by measuring both naphthalene transient decay at $410 \mathrm{~nm}$ and 9-cyanoanthracene transient formation at $460 \mathrm{~nm}$, under conditions of sample loading where decay of the benzophenone triplet was dominated through 25 quenching by naphthalene.. Bimolecular rate constants were extracted from plots of mean rate constant versus loading of the quenching species using eqn 2, as shown in Fig. 8.

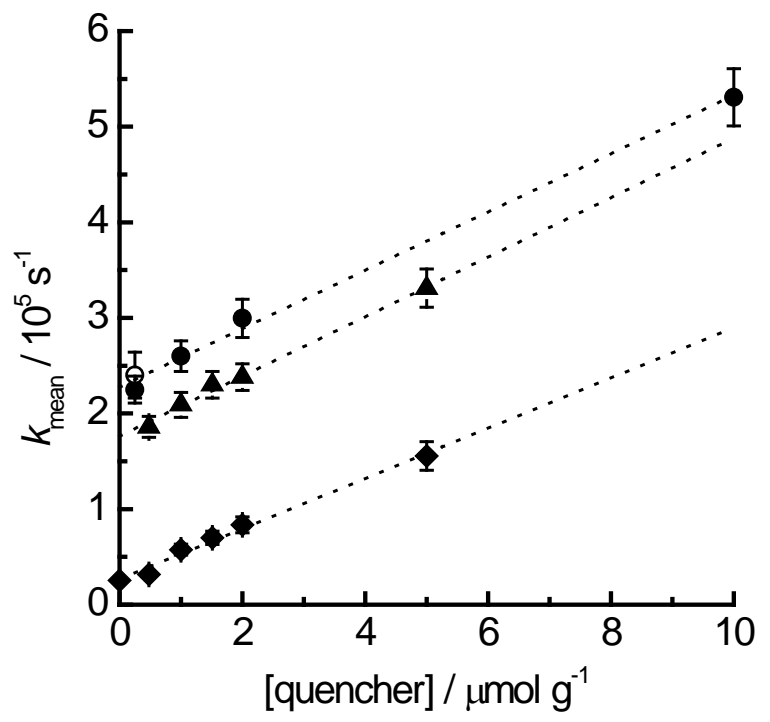

Fig. 8 Plot of mean rate constant versus quencher loading for 30 benzophenone phosphorescence decay $(\bullet)$ at $430 \mathrm{~nm}$ and benzophenone transient decay (O) at $520 \mathrm{~nm}$, naphthalene transient decay ( $)$ at $410 \mathrm{~nm}$ and 9-cyanoanthracene transient formation $(\boldsymbol{\Delta})$ at $460 \mathrm{~nm}$. Sample loadings were benzophenone at $50 \mu \mathrm{mol} \mathrm{g}^{-1}$ and varying naphthalene and 9-cyanoanthracene loadings from $0.1-10 \mu \mathrm{mol} \mathrm{g}^{-1}$.

A summary of the bimolecular rate constants obtained for energy transfer are given in Table 1.

Table 1 Bimolecular rate constants for energy transfer between 40 benzophenone (Bzp), naphthalene (Nap) and 9-cyanoanthracene (AnCN) with Nap or AnCN acting as the quencher (energy acceptor).

\begin{tabular}{lll}
\hline Process & Quencher & $k_{q}^{\prime} / \mathrm{g} \mathrm{mol}^{-1} \mathrm{~s}^{-1}$ \\
& & \\
\hline${ }^{45}{ }^{3} \mathrm{Bzp}^{*}$ decay & Nap & $3.0 \pm 0.2 \times 10^{10}$ \\
${ }^{3} \mathrm{Nap}^{*}$ decay & AnCN & $2.7 \pm 0.2 \times 10^{10}$ \\
${ }^{3} \mathrm{AnCN}$ formation & AnCN & $3.1 \pm 0.3 \times 10^{10}$ \\
& & \\
\hline
\end{tabular}

50 In all three cases the bimolecular rate constant for energy transfer to and from naphthalene is the same within experimental error, indicating that the process is dominated by the rapid mobility of naphthalene and its excited triplet state. An advantage of a termolecular system is being able to measure and 55 independently verify the same energy transfer step via different excited states as in the case here with naphthalene triplet state decay and 9-cyanoanthracene formation. 
The bimolecular rate constants were found to be similar to those previously measured in a bimolecular system for naphthalene / azulene energy transfer ${ }^{1}$ where $k_{\mathrm{q}}^{\prime}=2.21 \pm 0.1 \times$ $10^{10} \mathrm{~g} \mathrm{~mol}^{-1} \mathrm{~s}^{-1}$. The rate constants reported here are slightly 5 larger than previously reported values, which were assumed to be dominated by diffusional factors. The fact that larger rate constants are observed in this system demonstrates that diffusion is not the only factor which determines energy transfer rates, and that there are other factors which need to be considered. In 10 addition to the steric (entropic) contributions already discussed (vide supra). One possible explanation for this small difference may be comparitively unfavourable Franck-Condon factors for energy transfer between naphthalene and azulene given the strongly exothermic nature of this process, as can be seen from 15 the triplet state energies, $E_{\mathrm{T}}$, in Table 2.

Table 2 Energies of triplet excited states.

\begin{tabular}{ll}
\hline Compound & $E_{\mathrm{T}} / \mathrm{kJ} \mathrm{mol}^{-1}$ \\
\hline${ }^{20}$ & \\
\hline${ }_{25}$ & $289^{55}$ \\
& $255^{56}$ \\
benzophenone & $178^{57}$ \\
naphthalene & $177^{58}$ \\
anthracene-9-carboxylic acid & $169^{59}$ \\
anthracene & $163^{60}$ \\
9-cyanoanthracene & \\
azulene & \\
\hline
\end{tabular}

30 In previous studies we noted that the rate constants for energy transfer between anthracene / anthracene-9-carboxylic acid and azulene ${ }^{2}$ to be almost half that $\left(k_{\mathrm{q}}^{\prime}=1.0 \times 10^{10} \mathrm{~g} \mathrm{~mol}^{-1} \mathrm{~s}^{-1}\right)$ for naphthalane $^{1}$ to azulene, and suggested that this could be explained on the basis of relative diffusion coefficients. This 35 study however provides compelling evidence that there are additional factors factors involved in these systems. In addition to factors already discussed, it can further be suggested that in the anthracene / azulene system, where the excited triplet states lie close in energy, back energy transfer in the encounter complex is 40 possible leading to an apparent reduction in the observed rate. The temperature dependence of the observed rate constants will then reflect the competition between increased diffusion rates and increased back energy transfer as temperature is increased.

Clearly such effects are worthy of further exploration, and 45 these novel termolecular systems provide a powerful tool for studying these controlling factors in detail.

\section{Conclusions}

To our knowledge we have demonstrated energy transfer in a 50 termolecular system using a molecular shuttle on silica gel surfaces, for the first time. Rate constants for energy transfer in all steps of this process were found to be the same within experimental error, and slightly larger than rates previously reported in other systems. This suggests the latter are not fully
55 diffusion controlled, and other factors such as Franck-Condon factors, triplet state energies and steric considerations need to be taken into account. Additionally, we have demonstrated electron transfer in a termolecular system using azulene to transfer the electron hole between an immobile electron acceptor and electron 60 donor.

No electron transfer between anthracene-9-carboxylic acid and $\beta$-carotene is observed in the absence of azulene, verifying its role as an electron hole carrier. The rate of electron transfer in this system is significantly lower than that observed previously 65 using perylene as the final electron donor rather than $\beta$-carotene. We therefore suggest on this basis and that of previous studies ${ }^{1}$ that electron transfer reactions on the substrate are not only dependent on the relative mobility of the reacting species, but also strongly influenced by steric considerations such as size, 70 substitution and orbital symmetry.

This study demonstrates that termolecular systems can provide novel insights into energy and electron transfer processes on silica gel, and potentially other surfaces. It is also clear that, whilst diffusion plays the most significant role in determining 75 observed rates, energetic and steric factors influence the detailed rate behaviour.

\section{Acknowledgements}

The authors would like to thank Anisoara Vancea for assistance 80 with experimental measurements. We would also like to thank EPSRC for funding this project.

\section{Notes and references}

Department of Chemistry, Loughborough University, Loughborough, Leicestershire, LE11 3TU, United Kingdom. Fax: +44 (0)1509 223925; 85 Tel: +44 (0)1509 222567; E-mail: d.r.worrall@lboro.ac.uk

1. D. R. Worrall, I. Kirkpatrick and S. L. Williams, Bimolecular processes on silica gel surfaces: energetic factors in determining electron-transfer rates, Photchem. Photobiol. Sci., 2004, 3, 63-70.

902 . D. R. Worrall, I. Kirkpatrick and S. L. Williams, Controlling factors in electron and energy transfer reactions on silica gel surfaces, Photochem. Photobiol. Sci., 2002, 1, 896-901.

3. S. L. Williams, D. R. Worrall and I. Kirkpatrick, A. Vancea, J. Pan, Activation energies of photoinduced unimolecular, bimolecular and 95 termolecular processes on silica gel surfaces, Photochem. Photobiol. Sci., 2011, 10, 84-90.

4. S. L. Williams, I. Kirkpatrick and D. R. Worrall, Electron transfer reactions in ternary systems on silica gel surfaces: evidence for radical cation diffusion, Photochem. Photobiol. Sci., 2010, 9, 937941.

5. J. K. Thomas and E. H. Ellison, Various aspects of the constraints imposed on the photochemistry of systems in porous silica, Adv. Colloid Interface Sci., 2001, 89, 195-238.

6. F. Wilkinson, D. R. Worrall and S. L. Williams, Primary 105 Photochemical Processes of Anthracene Adsorbed on Silica-Gel, J. Phys. Chem., 1995, 99, 6689-6696.

7. D. R. Worrall, S. L. Williams and F. Wilkinson, Electron Transfer Reactions of Anthracene Adsorbed on Silica Gel, J. Phys. Chem. B, 1997, 101, 4709-4716.

110 8. D. Oelkrug, S. Reich, F. Wilkinson and P. A. Leicester, Photoionization on Insulator Surfaces - Diffuse Reflectance Laser Flash-Photolysis of Distyrylbenzenes Adsorbed on Silica and Alumina, J. Phys. Chem., 1991, 95, 269-274.

9. D. Oelkrug, S. Uhl, F. Wilkinson and C. J. Willsher, Bonding and 115 mobility of acridine on some metal-oxide surfaces as studied by 
delayed fluorescence and transient absorption-spectroscopy, J. Phys. Chem., 1989, 93, 4551-4556.

10. R. W. Kessler and F. Wilkinson, Diffuse reflectance triplet-triplet absorption-spectroscopy of aromatic-hydrocarbons chemisorbed on $\gamma$ alumina, J. Chem. Soc., Faraday Trans. 1, 1981, 77, 309-320.

11. I. K. Lednev, N. Mathivanan and L. J. Johnston, Photochemistry of Stilbene Adsorbed on Silica-Gel and NaX Zeolite - a DiffuseReflectance Laser Flash-Photolysis Study, J. Phys. Chem., 1994, 98, 11444-11451.

10 12. G. J. Kavarnos and N. J. Turro, Photosensitization by reversible electron-transfer - theories, experimental-evidence, and examples, Chem. Rev., 1986, 86, 401-449.

13. A. Liu, M. C. Sauer, D. M. Loffredo and A. D. Trifunac, Transient absorption spectra of aromatic radical cations in hydrocarbon

15 solutions, J. Photochem. Photobiol. A:Chem., 1992, 67, 197-208.

14. D. R. Worrall, S. L. Williams and F. Wilkinson, Electron transfer on insulator surfaces: Exciplex emission and the role of electron diffusion in determining radical deactivation rates, J. Phys. Chem. A, 1998, 102, 5484-5490.

20 15. D. R. Worrall, S. L. Williams, F. Wilkinson, J. E. Crossley, H. Bouas-Laurent and J.P. Desvergne, Spectroscopy and ion-electron recombination kinetics of radical ions of anthracenes and substituted anilines on silica gel, J. Phys. Chem. B, 1999, 103, 9255-9261.

16. S. Pankasem and J. K. Thomas, Pyrene, Pyrene Derivatives, and 1,1'Binaphthyl as Luminescent Probes for Photophysical Studies of Alumina Surfaces,. J. Phys. Chem., 1991, 95, 7385-7393.

17. S. Pankasem and J. K. Thomas, Reflectance Spectroscopic Studies of the Cation Radical and the Triplet of Pyrene on Alumina, J. Phys. Chem., 1991, 95, 6990-6996.

30 18. G. Beck and J. K. Thomas, Photochemical Processes on AluminumOxide - a Pulsed Laser Study of Photoinduced Reactions, Chem. Phys. Lett., 1983, 94, 553-557.

19. D. Oelkrug, G. Krabichler, W. Honnen, F. Wilkinson and C. J. Willsher, Photophysical Behavior of Diphenylpolyenes Adsorbed on

35 Alumina by Diffuse Reflectance Laser Flash-Photolysis,. J. Phys. Chem., 1988, 92, 3589-3594.

20. Y. Mao and J. K. Thomas, Photochemical-Reactions of Biphenyl and Its Chlorinated Derivatives on the Surfaces of Gamma-Alumina and Silica-Alumina, J. Chem. Soc.-Faraday Trans., 1992, 88, 3079-3086.

40 21. Y. Mao and J. K. Thomas, Photochemical-Reactions of Pyrene on Surfaces of Gamma-Alumina and Silica-Alumina, Langmuir, 1992, 8, 2501-2508.

22. K. K. Iu and J. K. Thomas, Photophysical Properties of Pyrene in Zeolites .2. Effects of Coadsorbed Water, Langmuir, 1990, 6, 471478.

23. L. J. Johnston, J. C. Scaiano, J. L. Shi, W. Siebrand and F. Zerbetto, Observation and Modeling of the Recombination Kinetics of Diphenylmethyl Radicals in the Cavities of Na-X Zeolite, J. Phys. Chem., 1991, 95, 10018-10024.

50 24. F. Wilkinson and R. Beer, Diffuse reflectance laser photolysis of adsorbed molecules, in Photochemical processes in organised molecular systems, K. Honda, Editor, 1991, Elsevier Science: Amsterdam. p. 377-398.

25. G. H. Zhang, J. K. Thomas, A. Eremenko, T. Kikteva and F. Wilkinson, Photoinduced charge-transfer reaction between pyrene and N,N'- dimethylaniline on silica gel surfaces, J. Phys. Chem. B, 1997, 101, 8569-8577.

26. D. Oelkrug, M. Gregor and S. Reich, Translational Mobility in the Adsorbed State - Bimolecular Deactivation Kinetics of Laser-Excited

60 Azaaromatics on Microporous Silica, Photochem. Photobiol., 1991, 54, 539-546.

27. D. Oelkrug, S. Uhl, F. Wilkinson and C. J. Willsher, Bonding and Mobility of Acridine on Some Metal-Oxide Surfaces as Studied by Delayed Fluorescence and Transient Absorption- Spectroscopy, $J$. Phys. Chem., 1989, 93, 4551-4556.

28. R. Krasnansky, K. Koike and J. K. Thomas, Gaussian Approximation to the Unique Heterogeneous Langmuir- Hinshelwood Type Fluorescence Quenching at the Silica-Gel Gas- Solid Interface Pyrene and 9,10-Diphenylanthracene Singlet Quenching by Oxygen, J. Phys. Chem., 1990, 94, 4521-4528.
29. S. A. Ruetten and J. K. Thomas, Fluorescence and triplet quantum yields of arenes on surfaces, J. Phys. Chem. B, 1998, 102, 598-606.

30. R. Dabestani, J. Higgin, D. Stephenson, I. N. Ivanov and M. E. Sigman, Photophysical and photochemical processes of 2-methyl, 275 ethyl, and 2-tert-butylanthracenes on silica gel, A substituent effect study. J. Phys. Chem. B, 2000, 104, 10235-10241.

31. S. Hashimoto, N. Fukazawa, H. Fukumura and H. Masuhara, Observation and Characterization of Excimer Emission from Anthracene Included in NaX Zeolite, Chem. Phys. Lett., 1994, 219, 445-451.

32. X. S. Liu, K. K. Iu, J. K. Thomas, H. Y. He and J. Klinowski, Spectroscopic Studies of Protonated Aromatic Species and Radical Cations in H+-Zeolites, J. Am. Chem. Soc., 1994, 116, 11811-11818.

33. H. Garcia and H. D. Roth, Generation and reactions of organic radical cations in zeolites, Chem. Rev., 2002, 102, 3947-4007.

34. M. Alvaro, P. Ateinzar, A. Corma, B. Ferrer, H. Garcia and M. T. Navarro, Photochemical Generation of Electrons and Holes in Germanium-Containing ITQ-17 Zeolite, J. Phys. Chem. B, 2004, 109, 3696-3700.

90 35. I. Batonneau-Gener, A. Moissette, C. Bremard and G. Buntinx, Time resolved resonance Raman, transient diffuse reflectance and kinetic studies of species generated by UV laser photolysis of biphenyl occluded within dehydrated Y-faujasite zeolites, J. Photochem. Photbiol. A: Chemistry, 2008, 195, 156-166.

95 36. R. Dabestani, M. Kidder and A. C. Buchanan, Pore size effect on the dynamics of excimer formation for chemically attached pyrene on various silica surfaces, J. Phys. Chem. C, 2008, 112, 11468-11475.

37. J. M. Stokke and D. W. Mazyck, Photocatalytic degradation of methanol using silica-titania composite pellets: Effect of pore size on mass transfer and reaction kinetics, Environmental Science and Technology, 2008, 42, 3808-3813.

38. J. P. Da Silva, E. V. Bastos, L. Vieira Ferreira and R. G. Weiss, Surface photochemistry of the herbicide napropamide. The role of the media and environmental factors in directing the fates of intermediates, Photochem. Photobiol. Sci., 2008, 7, 69-75.

39. L. F. Vieira Ferreira, J.P. Da Silva, I. Ferreira Machadoa, T.J.F. Branco and J.C. Moreira, Surface photochemistry: Dibenzo-p-dioxin adsorbed onto silicalite, cellulose and silica, J. Photochem. Photbiol. A: Chemistry, 2007, 186, 254-262.

10 40. L. F.Vieira Ferreira, J. P. Da Silva, I. Ferreira Machadoa and T. J. F. Branco, Surface photochemistry: benzophenone as a probe for the study of silica and reversed-phase silica surfaces, Photochem. Photobiol. Sci., 2006, 5, 665-673.

41. M. Alvaro, P. Ateinzar, A. Corma, B. Ferrer, H. Garcia and M. T. 115 Navarro, Photochemical Generation of Electrons and Holes in Germanium-Containing ITQ-17 Zeolite, J. Phys. Chem. B, 2004, 109, 3696-3700.

42. S. Takagi, D. A. Tryk and H. Inoue, Photochemical Energy Transfer of Cationic Porphyrin Complexes on Clay Surface, J. Phys Chem. B, 2002, 106, 5455-5460.

43. S. Takagi, T. Shimada, M. Eguchi, T. Yui, H. Yoshida, D. A. Tryk and H. Inoue, High-Density Adsorption of Cationic Porphyrins on Clay Layer Surfaces without Aggregation: The Size-Matching Effect, Langmuir, 2002, 18, 2265-2272.

125 44. M. Egucji, S. Takagi, H. Tachibana and H. Inoue, The 'size matching rule' in di-, tri-, and tetra-cationic charged porphyrin/synthetic clay complexes: effect of the inter-charge distance and the number of charged sites, Journal of Physics and Chemistry of Solids, 2004, 65, 403-407.

130 45. S. Takagi, M. Eguchi, D. A. Tryk and H. Inoue, Light-Harvesting Energy Transfer and Subsequent Electron Transfer of Cationic Porphyrin Complexes on Clay Surfaces, Langmuir, 2006, 22, 14061408.

46. W. J. Albery, P. N. Bartlett, C. P. Wilde and J. R. Darwent, A 135 General-Model for Dispersed Kinetics in Heterogeneous Systems, $J$. Am. Chem. Soc., 1985, 107(7), 1854-1858.

47. D. R. Worrall and S. L. Williams, Diffuse-Reflectance Laser Flash Photolysis, Encyclopedia of Modern Optics Volume 1, Guenther, R. D., Steel, D. G. and Bayvel, L. (eds), Elsevier, Oxford, 2004, pp 31$140 \quad 38$, ISBN 0-12-227600-0. 
48. D. Niedzwiedzki, J. F. Rusling and H. A. Frank, Voltammetric redox potentials of carotenoids associated with the xanthophyll cylce in photosynthesis, Chem. Phys. Lett., 2005, 415, 308-312.

49. J. A. Jeevarajan, C. C. Wei, A. S. Jeevarajan and L. D. Kispert, Optical Absorption Spectra of Dications of Carotenoids, J. Phys. Chem., 1996, 100, 5637-5641.

50. E. J. Land, D. Lexa, R. V. Bensasson, D. Gust, T. A. Moore, A. L. Moore, P.A. Liddell and G. A. Nemeth, Pulse Radiolytic and Electrochemical Investigation of Intramolecular Electron Transfer in

10 Carotenoporphyrins and Carotenoporphyrin-Quinone Triads, J. Phys. Chem., 1987, 91, 4831-4835.

51. J. Lafferty, A. C. Roach, R. S. Sinclair, T. G. Truscott and E. J. Land, Absorption Spectra of Radical Ions of Polyenes of Biological Interest, J. Chem. Soc., Faraday Trans. 1, 1977, 73, 416-429.

15 52. N. J. Turro, M. B. Zimmit and I. R. Gould, triplet Energy treansfer as a Probe of Surface Diffusion Rates: A Time-Resolved Diffuse reflectance Transient Absorption Spectroscopy Study, J. Am. Chem. Soc., 1985, 107, 5826-5827.

53. N. J. Turro, I. R. Gould, M. B. Zimmit and C. Cheng, Ketone

20 Photochemistry on solid silica. A diffuse reflectance laser flash photolysis study, Chem. Phys. Lett., 1985, 119, 484-488.

54. E. vander Donckt, M. R. Barthels and A. Delestinne, Quantum yields of triplet formation of 9-cyanoanthracene in three solvents, $J$. Photochem., 1973, 1, 429-432.

25 55. W. J. Leigh and D. R. Arnold, Merostabilization in radical Ions, Triplets and Biradicals. Sybstituent Effects on the n, $\pi^{*}$ Triplet Energy of Benzophenone, J. Chem. Soc., Chem. Commun., 1980, 406-408.

56. G. N. Lewis and M. Kasha, Phosphorescene and the Triplet State, J.

$30 \quad$ Am. Chem. Soc., 1944, 66, 2100-2116.

57. S. Hirayama, Effect of Substituent on the Behaviour of the Excited Singlet and Triplet States in Carbonyl Derivatives of the Type 9X·CO·A, J. Chem. Soc., Faraday Trans. I, 1982, 78, 2411-2421

58. D. F. Evans, Perturbation of Singlet-Triplet Transitions of Aromatic

35 Molecules by Oxygen under Pressure, J. Chem. Soc., 1959, 13511357.

59. F. Wilkinson, D. J. McGarvey and A. F. Olea, Factors Governing the Efficiency of Singlet Oxygen Production during Quenching of Singlet and Trilet States of Anthracene Derivatives in Cyclohexane

40 Solution, J. Am. Chem. Soc., 1993, 115, 12144-12150.

60. W. G. Herkstroeter, The triplet Energies of Azulene, $\beta$-carotene, and Ferrocene, J. Am. Chem. Soc.,1975, 97, 4161-4167. 